\title{
RELATIONSHIP OF MIXED-LINK BETA-GLUCAN ACCUMULATION TO ACCUMULATION OF FREE SUGARS AND OTHER GLUCANS IN THE DEVELOPING BARLEY ENDOSPERM
}

\author{
by \\ GRAEME COLES \\ Department of Biotechnology, Carlsberg Research Center, \\ Gamle Carlsberg Vej 10, DK-2500 Copenhagen Valby \\ and \\ Crop Research Division, D.S.I.R., \\ Private Bag, Christchurch, New Zealand \\ (Address for reprint requests)
}

Keywords: Malting barley, enzymatic methods, starch, hemicellulose

\begin{abstract}
Accumulation of free sugar, starch, mixed-link beta-glucan and hemicellulose in developing barley endosperms was investigated using a sequential enzymatic procedure. Bomi grown in a growth cabinet, the three cultivars Minerva, Lami and Triumph, grown in the field, and Minerva and Triumph grown under a range of water supply regimes in the phytotron were studied.

The first experiments showed that initiation of synthesis occurred in the order hemicellulose, starch, mixed-link beta-glucan 10 days, 11 days, and 17 days after fertilization, respectively. The second experiment indicated two separate accumulation patterns for mixed-link beta-glucan, one shared by Lami and Triumph, the other followed by Minerva. When moisture content declined to $40-50 \%$, the accumulation rate increased sharply in Lami and Triumph, but not in Minerva. A similar sharp increase in the rate of accumulation of hemicellulose was observed in Minerva and Triumph.

The moisture stress experiment showed that water supply and humidity are the major factors mediating the response of beta-glucan content to environment, but that Triumph, a low-content genotype, was always lower in beta-glucan content than Minerva.

Some implications of the results for elucidation of the control of endosperm development are discussed.
\end{abstract}

\section{INTRODUCTION}

A good deal of attention has been paid to the accumulation of reserve substances in cereals $(2$, $3,7,8,18,19,20,21,23,24,25,26,27,28$, 30, 31). Among the carbohydrates, however, only free sugars and starch have been examined in any depth. The existence of two peaks of free sugar content, at the beginning of drymatter accumulation is well documented, $(2,3,8,18$, $19,25,26,27,31)$, but results for initiation, 
termination, and rate of accumulation of starch, and initial and final contents vary substantially from author to author $(3,8,19,20,23,25,26$, $28,31,38$ ).

In light of this it can be seen that a definitive method for following the accumulation of glucosan fractions in barley needed to be found. Little investigation of non-starch glucan accumulation has been made, except as pentosan and "crude fibre» by CERNING and GuILBOT (8) and MACGREGOR et al. (28). However, beta-glucans play an important structural role in the endosperm, comprising $75 \%$ of total cell wall composition $(12,13,14)$, but rather less in the aleurone layer, where arabino-xylan is the dominant polysaccharide. Moreover, in both brewing $(11,14,32,33,36)$ and animal feeding $(16,37)$ they are of considerable importance.

Cell-free synthesis of beta-glucan has been achieved with Lolium spp endosperm tissue culture preparations (34) and with many vegetative tissues (9). Screening methods for flour betaglucan content, based on the viscosity it induces in aqueous extracts, have been devised by BENDELOW (5) and MORGAN (32), and used to study the inheritance of barley flour extract viscosity (1). However, the in vivo synthesis of beta-glucans has not previously been studied in barley, so a method of assaying specific glucan fractions sequentially has been devised and used to study four commercial barley cultivars with different malting properties. By this means data were obtained to describe the relationship between accumulation curves of free sugar, starch, beta-1,3:1,4-glucan and other beta-glucans in a single cultivar. Then comparisons were made for each of the glucosans, and finally the accumulation process for beta-1,3:1,4-glucan was studied in two of the cultivars (Minerva and Triumph) under a range of water supply regimes in a phytotron.

\section{MATERIALS AND METHODS \\ 2.1. Materials}

Amyloglucosidase was a standard preparation from Boehringer Mannheim (Batch numbers 1308407, 1079407) having approx. $14 \mathrm{U} \cdot \mathrm{mg}^{-1}$. Incubation of a solution of pure beta-glucan from barley, supplied by the Department of Brewing Chemistry, Carlsberg Research Center, with $1 \mathrm{mg} \cdot \mathrm{g}^{-1}$ of amyloglucosidase at $\mathrm{pH} 4.5$, $65{ }^{\circ} \mathrm{C}$ for 24 hours produced no glucosecontaining oligosaccharides, indicating that the preparations were beta-glucanase-free.

Lichenase (E.C. 3.2.1.73) was the kind gift of Dr. B. S. Enevoldsen, of the Department of Brewing Chemistry, and it had an activity of $0.47 \mathrm{U} \cdot \mathrm{ml}^{-1}$ when diluted ready for use.

Cellulases from Aspergillus spp $\left(1 \mathrm{U} \cdot \mathrm{mg}^{-1}\right)$ and Trichoderma viride $\left(0.5 \mathrm{U} \cdot \mathrm{mg}^{-1}\right)$ were obtained from Koch-Light laboratories, Colnbrooke, England and Boehringer Mannheim, respectively.

Glucose oxidase assays of glucose content were made using the God-Perid system from Boehringer Mannheim.

All other chemicals used were analytical grade, glass-distilled water was used throughout, and standard $96 \%$ ethanol was used for preparing solvents. During all incubations two drops of toluene were added to inhibit bacterial growth.

\subsection{Growth room study}

\subsubsection{Plants}

Seeds of Hordeum vulgare cv. Bomi were sown in individual pots in a standard potting mixture. Once the coleoptiles appeared the plants were placed on fibrous matting kept moist with a capillary watering system. The plants were grown in a growth room with a 16 hour day at $12^{\circ} \mathrm{C}$ and an 8 hour night at $6^{\circ} \mathrm{C}$. Relative humidity was maintained at approx. $70 \%$. Light intensity at the bottom of the heat filter was 5.3 $\times 10^{3}$ lux. A light infection of powdery mildew (Erysiphe graminis) was present on senescing leaves, too late to have any real effect on assimilate contribution. Some sterility occurred in the tips of all ears, and occasionally scattered randomly along the ear.

\subsubsection{Selection and harvest of material}

Spikes on the point of flowering were labelled and noted. Since the number of plants was limited each had to supply a number of spikes, and these flowered over a period of approx. 6 days. By harvesting the last-flowering spikes first, and vice versa, it was possible to compress the harvest period considerably. For the purpo- 
ses of this experiment spikes were required at two-day intervals from 7-33 days after flowering, and 4 were harvested at each interval.

\subsection{Field study}

\subsubsection{Plants}

Hordeum vulgare cvv. Minerva, Lami and Triumph were grown in adjacent $15 \mathrm{~m}^{2}$ plots on a highly-fertile, heavy clay soil. Phosphorus and potassium were supplied to the soil in the previous autumn $\left(66 \mathrm{~kg}\right.$ per ha $\mathrm{P}_{2} \mathrm{O}_{5}$ and $88 \mathrm{~kg}$ per ha $\left.\mathrm{K}_{2} \mathrm{O}\right)$ and nitrogen supplied as $\mathrm{Ca}\left(\mathrm{NO}_{3}\right)_{2}$ at $90 \mathrm{~kg}$ per ha just before sowing. Mildew attacked less severely than usual, while yellow rust and barley rust (Puccinia glumarum and $P$. hordei, respectively) were worse than usual ( $J$. LARSEN pers. commun.).

Despite a somewhat dry spring, flowering occurred at the usual time, but the period thereafter was cold and wet, delaying harvest by several weeks.

\subsubsection{Selection and harvest of material}

As in the growth room study spikes on the point of flowering were labelled, but only primary spikes were used and all were labelled on the same day. All spikes were chosen from the centre of the plots. From 10 days after flowering three spikes were collected from each plot twice weekly, immediately frozen in liquid nitrogen and stored at $-70^{\circ} \mathrm{C}$ until needed for analysis. Sampling continued until harvestripeness.

\subsubsection{Moisture content}

The moisture content of all freshly-thawed Lami samples was determined by freeze-drying then oven-drying to constant weight at $130^{\circ} \mathrm{C}$.

\subsubsection{Micromalting}

Micromalting and malt analysis were carried out in the Central Laboratories of the Carlsberg Breweries according to the methods of GJERTSEN et al. (15).

\subsection{Phytotron study}

\subsubsection{Plants}

Hordeum vulgare crv. Minerva and Triumph were grown as single plants in pots on trolleys in the phytotron of the Royal College of Forestry in Stockholm $(1,39)$. The plants were grown on a sterile substrate of fine stones, sand and perlite, nutrient being supplied by watering with dilute Hoagland solution until the plants water requirements were satisfied. Until flowering the plants were kept in continuous light with 16 hours at $15^{\circ} \mathrm{C}$ followed by 8 hours at $10^{\circ} \mathrm{C}$. All spikes were date-labelled as they emerged, and the date of fertilisation determined. At this time the plants were moved to a room maintained continuously at $20^{\circ} \mathrm{C}$ and new watering regimes commenced as follows. Each treatment was given to seven plants of each cultivar.

1. "Rain « treatment. Water was given to the plants 12 hours in every 24 by an overhead spray (1) giving $2 \mathrm{sec}$ bursts of rain followed by pauses of $45 \pm 11$ secs. $200 \mathrm{ml}$ of Hoaglands solution were supplied to each pot at the end of each 12 hour rain period until the last week of the experiment, when only two additions were made, 4 days apart.

2. "Root" treatment. Water was supplied to the plants in this treatment by a capillary tube at such a rate that the amount passing through the pots in any 24 hour period was the same as in treatment 1 .

3. "Control « treatment. $200 \mathrm{ml}$ of Hoaglands solution were supplied to each pot morning and evening for 31 days, and the amount of water passing through all the pots was measured for each 24 hour period. In the last week of the experiment the watering was reduced to once daily, with Hoaglands solution being replaced by deionised water except on the 2 nd and 6 th days.

4. "Reduced water" treatment. $200 \mathrm{ml}$ of Hoaglands solution were given to each pot each morning for nine days. For the following 22 days $200 \mathrm{ml}$ were given every second day. In the final week of the experiment $200 \mathrm{ml}$ of Hoaglands solution were given on the 2 nd and 6th days, and $200 \mathrm{ml}$ of deionised water on the 4 th day.

5. "Control-reduced" treatment. As for treatment 3 for 20 days, then as treatment 4 for the rest of the experiment.

6. »Reduced-controk treatment. As for treat- 
ment 4 for 20 days, then as for treatment 3 for the rest of the experiment.

\subsubsection{Harvesting}

Samples of five spikes were harvested from each cultivar at $14,18,22,26,30,35$ and 40 days after fertilisation. From each sample 10 kernels were removed ( 2 from the middle of each spike), weighed and placed in a stoppered tube, which was then placed in the freezer in a plastic bag with the remainder of the sample.

\subsubsection{Moisture content}

The moisture content of the kernels separated as above was determined as in section 2.3.3.

\subsection{Analysis}

\subsubsection{Preparation of samples for analysis}

When harvesting was completed, the developing grains were removed from their lemmae and paleae. The embryo, and as much of the pericarp as possible, was removed. The prepared grains are referred to as endosperms in the text.

In some treatments the embryos of some Triumph kernels continued to grow into plantlets without a pause i.e. viviparously (6); these seeds were excluded from the samples when they were found. Each sample was freeze-dried and weighed. The endosperms were stored in airtight containers at $-20^{\circ} \mathrm{C}$ until required for analysis, at which time they were ground, where possible, in a Tecator CycloTec sample mill (Tecator Inc., Boulder, Colorado, U.S.A.) and a sample drawn for dryweight determination (section 2.3.3). The equilibrium moisture content was thus found and used to convert all subsequent data to a drymatter basis. Duplicate samples of between 100 and $200 \mathrm{mg}$ of freeze-dried tissue were weighed into $30 \mathrm{ml}$ stoppered centrifuge tubes.

\subsubsection{Extractions}

\subsubsection{Free sugar}

In this class is included all the carbohydrate soluble in $80 \%$ ethanol (v/v) (35). To each sample $25 \mathrm{ml}$ of $80 \%$ ethanol was added and the material thoroughly suspended. In the cases where it proved impossible to grind the tissue the whole endosperms were weighed out, covered with $10 \mathrm{ml}$ of solvent and dispersed with a Polytron tissue homogeniser (Kinematica $\mathrm{GmbH}$, Lucerne, Switzerland). The homogeniser was carefully washed with a further $15 \mathrm{ml}$ of solvent, which was added to the homogenate. Thereafter these samples were treated exactly as the ground tissue.

The samples were occasionally resuspended over a period of an hour, then sedimented in a bench centrifuge at $1500 \mathrm{~g}$ for $10 \mathrm{~min}$, and the supernatants transferred to round-bottomed flasks. The pellets were extracted a further three times.

The combined supernatants were concentrated on a rotary evaporator until most of the ethanol was removed, then frozen and freeze-dried. When quite dry all water-soluble material was redissolved in $40 \mathrm{ml}$ of water, leaving a precipitate of lipids and protein, which was removed by centrifugation. The resultant supernatants were stored at $-20^{\circ} \mathrm{C}$ until needed for analysis.

\subsubsection{Starch}

The free-sugar-free pellets were resuspended in $8 \mathrm{ml}$ of water and heated to $90^{\circ} \mathrm{C}$ in a waterbath for an hour. Upon cooling $2 \mathrm{ml}$ of 0.1 $\mathrm{M}$-sodium acetate buffer $(\mathrm{pH} 4.5)$ were added and the $\mathrm{pH}$ adjusted if necessary. Amyloglucosidase was added at the rate of $2 \mathrm{mg} \cdot \mathrm{g}^{-1}$ of sample and an incubation carried out at $65^{\circ} \mathrm{C}$ for 16 hours. The incubation was stopped by the addition of 2.5 volumes of $96 \%$ ethanol and the tubes stood in the cold. Precipitates were pelletted in the bench centrifuge and washed as in section 2.5.2.1.

\subsubsection{Mixed-link beta-glucan}

The extraction and analytical methods were derived from ANDERSON et al. (4), with modifications to take account of the small samples and the sequential nature of the determinations.

The starch-free pellets from section 2.5.2.2. were resuspended in $10 \mathrm{ml}$ of $0.05 \mathrm{M}$-sodium maleate buffer $(\mathrm{pH} \quad 6.5)$ and warmed in a waterbath to $90{ }^{\circ} \mathrm{C}$ for $10 \mathrm{~min}$. After cooling to room temperature $0.100 \mathrm{ml}$ of lichenase solution were added to each tube and incubation carried 
G. D. CoLEs: Beta-glucan accumulation in barley
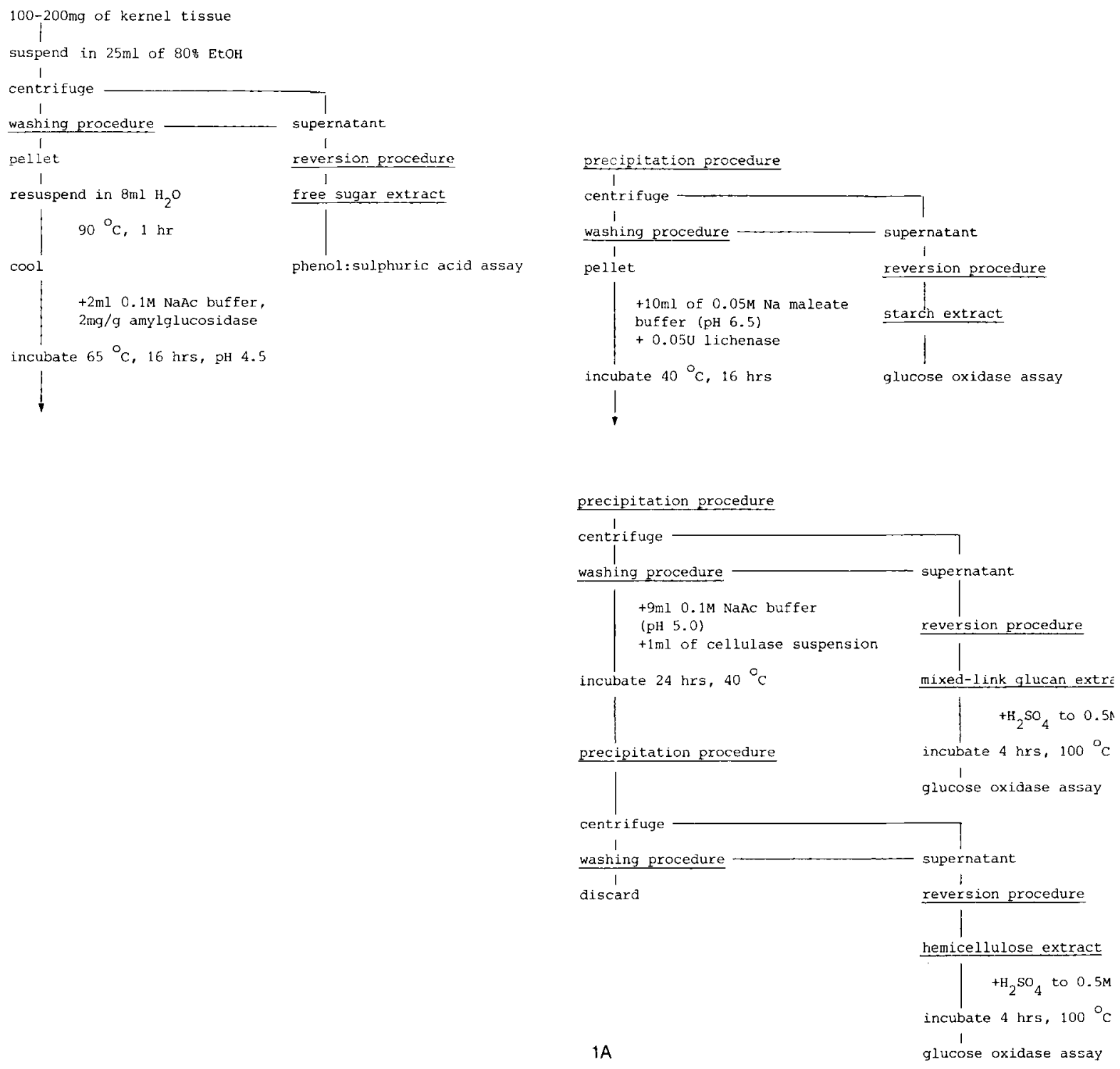

\section{precipitation procedure}

add 2.5 vols $96 \% \mathrm{EtOH}$ stand in stand in the cold $\left\{2-4{ }^{\circ} \mathrm{C}, 4\right.$ hrs $\}$

$1 B$ glucose oxidase assay

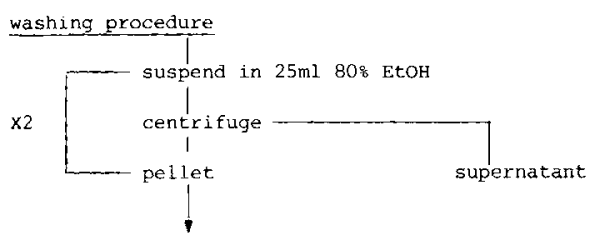

$1 \mathrm{C}$

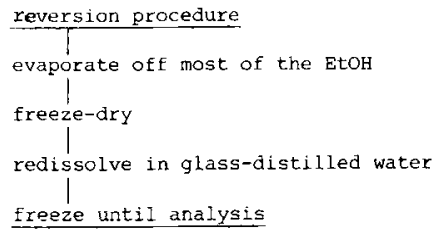

10

Figure 1.

A. Flowchart representing the temporal relationship between the processes outlined in part 2.5.2.

B. Outline of the procedure used to stop incubations and precipitate unhydrolysed polysaccharide.

C. Outline of the procedure used to extract liberated oligosaccharide.

D. Outline of the procedure used to prepare extracts for analysis. 
out at $40{ }^{\circ} \mathrm{C}$ for 16 hours. Soluble sugars released by this procedure were extracted as above and prepared for further analysis.

\subsubsection{4. "Hemicelluloser}

This class included all beta-linked glucosans not released from the samples by previous treatments. Since the majority of these molecules are long chains of beta-1,4-linked glucose residues the term hemicellulose will be used, for convenience, if not strict accuracy. The pellets from the preceding procedure were resuspended in $9 \mathrm{ml}$ of $0.1 \mathrm{M}$-sodium acetate buffer ( $\mathrm{pH} \mathrm{5.0)}$ and $1 \mathrm{ml}$ of the buffer, containing $5 \mathrm{mg}$ each of the cellulases described in section 2.1, were added to each. The incubations were carried out at $40{ }^{\circ} \mathrm{C}$ for 24 hours and the released sugars extracted as described in section 2.5.2.1. The procedures outlined in section 2.5.2. are summarised in Figure 1.

\subsubsection{Estimation of released sugar}

\subsubsection{Free sugars}

Estimation was by the method of DuBors et al. (10), modified for use on a smaller scale. To 0.5 $\mathrm{ml}$ of a solution containing $0.020-0.100 \mathrm{mg}$ of sugar per $\mathrm{ml}, 0.050 \mathrm{ml}$ of a mixture of 4 parts of phenol to 1 part of water $(\mathrm{w} / \mathrm{w})$ was added, and to this mixture, $1.5 \mathrm{ml}$ of $97 \% \mathrm{H}_{2} \mathrm{SO}_{4}$ were added and mixed immediately, to ensure the most sensitive colour reaction (10). After $30 \mathrm{~min}$ a further $1.5 \mathrm{ml}$ of $\mathrm{H}_{2} \mathrm{SO}_{4}$ were added and the absorbance measured in a Jasco Uvidec-1 spectrophotometer, against a blank containing no sugar, at $490 \mathrm{~nm}$. Quadruplicate samples were prepared to guard against error due to contamination and insufficient mixing. It was found necessary to mix the samples thoroughly in the cuvette to obtain stable absorbance values.
Provided these precautions were taken standard deviations between replicates of less than $2 \%$ were obtained. Absorbance values were converted to sucrose equivalents by comparison to sucrose standards and a standard curve.

\subsubsection{Glucose-containing hydrolysates}

The starch extract could be assayed directly, but others had first to be hydrolysed to glucose. $1.5 \mathrm{ml}$ of the aqueous extract were placed in a 4 $\mathrm{ml}$ glass tube, and $0.5 \mathrm{ml}$ of $2 \mathrm{M}-\mathrm{H}_{2} \mathrm{SO}_{4}$ added. The tube was placed in a larger tube which was sealed and heated to $100{ }^{\circ} \mathrm{C}$ for 4 hours. This treatment breaks glycosidic linkages without breaking internal bonds of glucose (8). At the conclusion of the treatment the tube was opened and the contents of the smaller tube neutralised with $2 \mathrm{ml}$ of $1 \mathrm{~m}-\mathrm{NaOH}$.

Hydrolysates were analysed for glucose content using the glucose oxidase method (section 2.1) with some modifications, in that only $4 \mathrm{ml}$ of test solution were used, and that triplicates were analysed. Standards were run at the beginning of each batch, since generally more than the recommended number of samples were run at a time. Standard deviation of test results was typically less than $1 \%$. Results were calculated as glucose released and converted to polysaccharide hydrolysed using a factor of 0.9 (formula weight glucoside residue divided by molecular weight of glucose).

\subsubsection{Protein content}

Protein content of samples from the phytotron experiment was measured using a semi-automated Kjeldahl method (Tecator Instruments $A B$, Helsingborg, Sweden) with a selenium catalyst and converted to protein using the factor $6.25 \times \mathrm{N}$.

Figure 2. Accumulation of glucosans in Bomi barley.

a. Accumulation of free sugar. ( ) free sugar as a percentage of endosperm dryweight. ( $\square$ ) free sugar content, $\mathrm{mg}$ per endosperm. $\mathbf{b}$. Accumulation of drymatter $(\bullet)$ and $\operatorname{starch}(\boldsymbol{\square})$ in $\mathrm{mg}$ per endosperm. c. Accumulation of mixed-link beta-glucan $(\boldsymbol{\square})$ and hemicellulose $(\bullet)$ in $\mathrm{mg}$ per endosperm. Horizontal axes: days after fertilisation. 

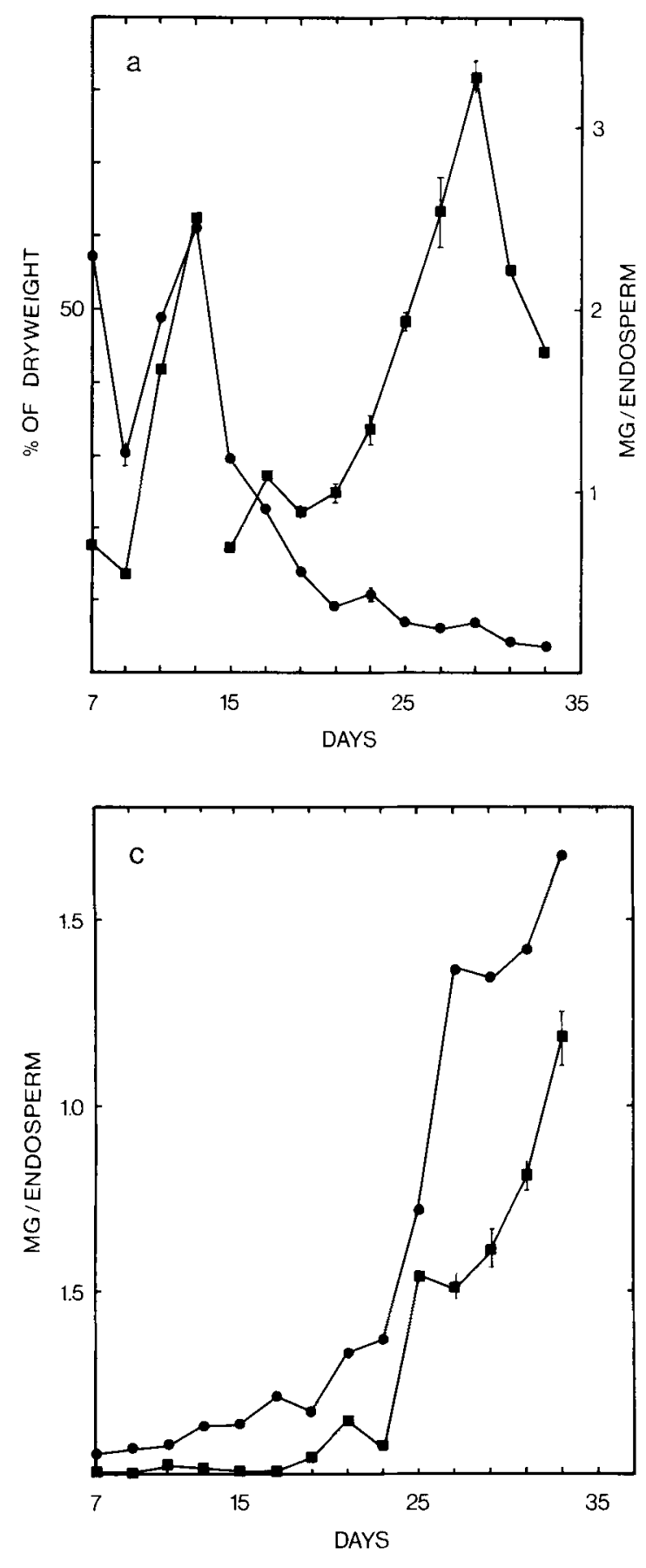

\section{RESULTS}

\subsection{Growth room study}

Results are given in graphical form in Figure 2. Figure 2a shows how free sugar content fluctuated in the developing endosperm, in both

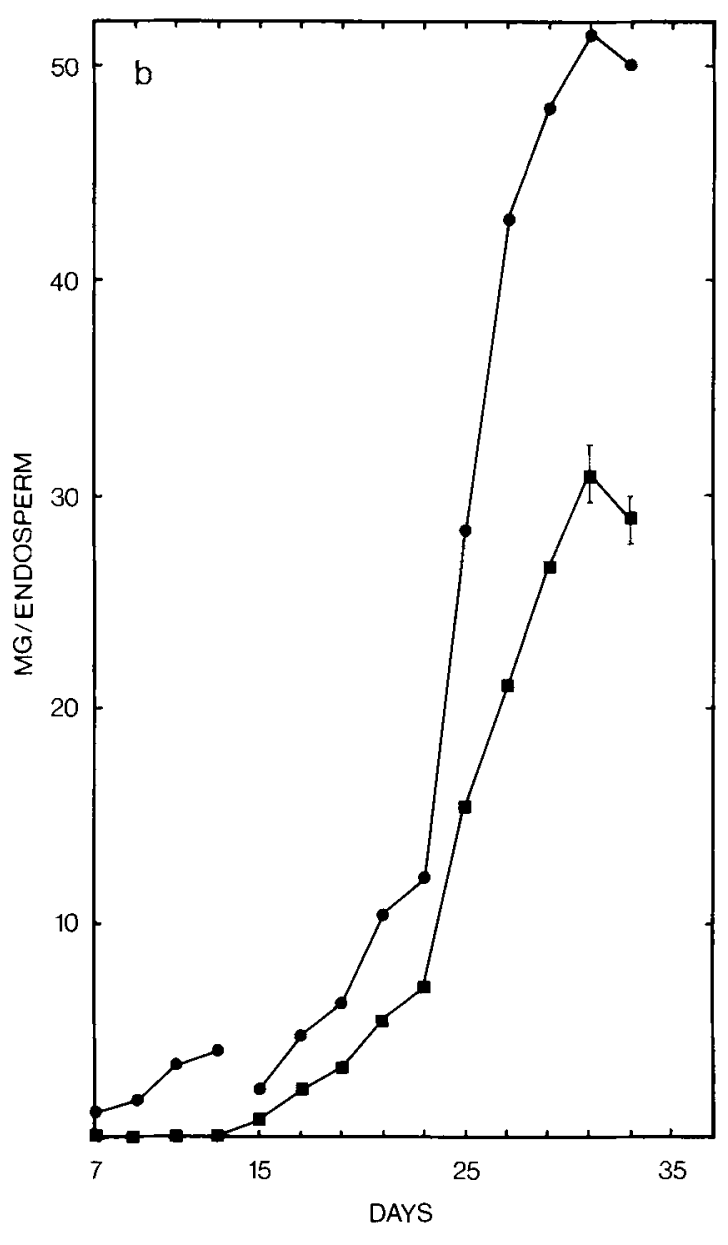

percentage terms and in terms of $\mathrm{mg}$ per endosperm. Percentage free sugar content follows a well-established path, increasing to a peak of about $50 \%$ at 10-12 days after flowering, then declining until maximum drymatter content is reached, when a second small peak may be observed. The curves found for Bomi in this experiment and in the field in 1976 by KreIs (26) are very similar in shape. The discontinuity between day 13 and day 15 arose because day 15 was the first day it was possible to extract an endosperm from the pericarp. Previously the pericarp was included in the samples, but only the curve of $\mathrm{mg}$ free sugar per endosperm was affected. Measurement of free sugar content of kernels with and without pericarp at 15 days gave similar results. Starch content is low until 
day 13 , but begins to increase rapidly between days 13 and 15 , in tandem with endosperm dryweight, and reaches a maximum at day 31 , at which time dryweight also peaks.

Hemicellulose and mixed-link beta-glucan accumulation curves are given in Figure 2c. First evidence of synthesis is found at 11 days for hemicellulose, and at 17 days for mixed-link beta-glucan, but synthesis lags behind endosperm dryweight increase until 15 days and 2123 days, respectively.

\subsection{Field study}

The results of this investigation are presented in Table $I$ and Figures 3 and 4.

\section{Table 1}

Analysis of malt prepared from the lines of Minerva, Lami and Triumph used in the field experiment (section 3.2)

\begin{tabular}{lccc}
\hline & Minerva & Lami & Triumph \\
\hline Kernel protein, \% & 13,1 & 11,6 & 12,2 \\
Wort Viscosity, cP & 1,80 & 1,71 & 1,61 \\
Extract, \% & 76,9 & 77,6 & 81,2 \\
Soluble N mg $100 \mathrm{ml}^{-1}$ & 80 & 80 & 98 \\
\hline
\end{tabular}

Table I indicates the malting quality of the lines of the three cultivars that were investigated. The data obtained rank the cultivars Triumph Lami - Minerva in descending order of malting quality by virtue of the decrease in extract and increase in wort viscosity found when listing the cultivars in this order. This is the result normally obtained when comparing these cultivars.

Figure $3 \mathrm{a}$ gives the results of dryweight determinations on endosperms of the three cultivars at each sampling date, and the curve of moisture content decline in Lami over the sampling period. After an initial period of very high moisture content the decline from $65 \%$ at day 14 to $43 \%$ at day 38 is linear. Thereafter the decline is steeper.

The curves of endosperm drymatter accumulation coincide closely with one another until day 45, after which Triumph stops. The final outcome was that Triumph had a somewhat lower final endosperm dryweight than Minerva or Lami.

Free sugar curves are presented in Figure $3 b$ and can be used to relate the time scale of this experiment to that of the growth room experiment (section 3.1). The two peaks of free sugar content occur at days 10 and 35 in this experiment, and the comparable peaks are found in Bomi at days 13 and 29, implying that
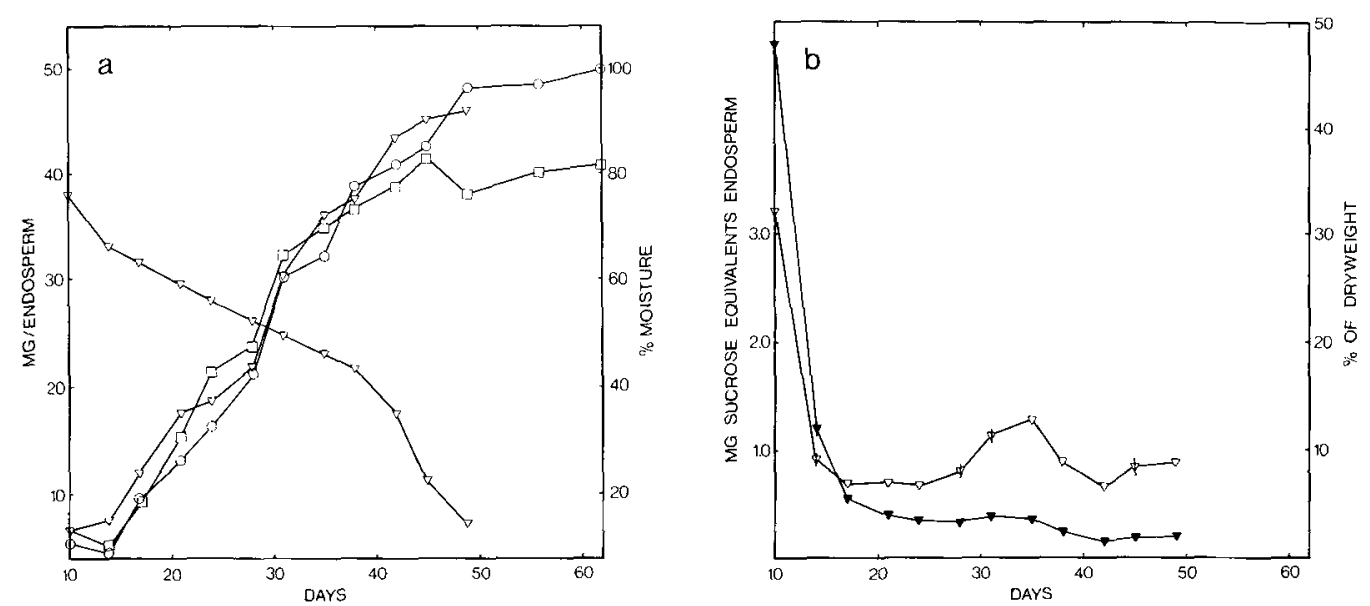

Figure 3. Accumulation of glucosans in Minerva (O), Lami $(\nabla)$ and Triumph $(\square)$ as a function of time.

a. Accumulation of drymatter (ascending curves). The descending curve gives the moisture content of Lami endosperms during the growth period.

b. Free sugar content of Lami endosperms during the growth period. (Solid triangles: \% of dryweight. Open triangles: mg per endosperm). Horizontal axes: days after fertilisation. 

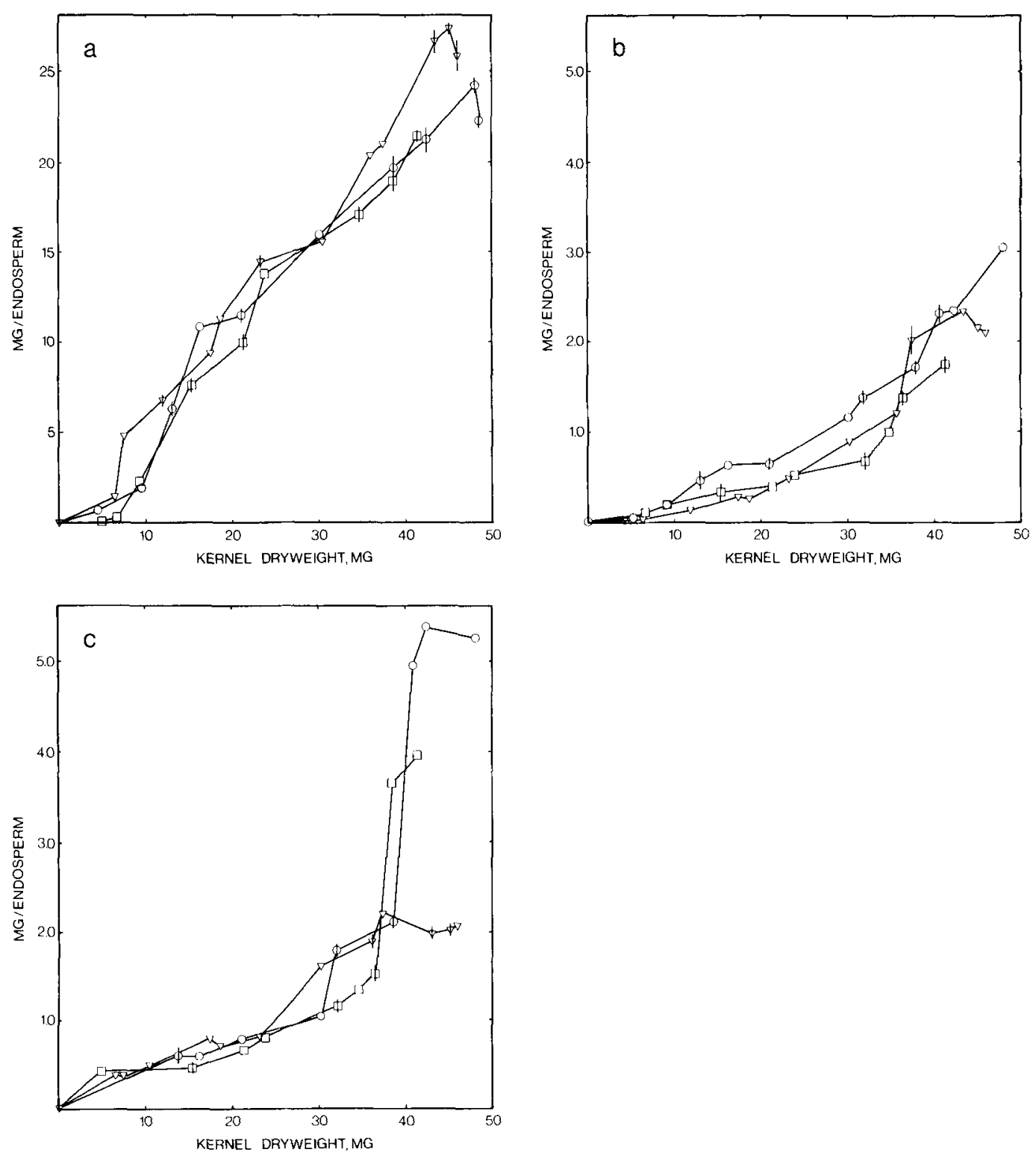

Figure 4. Accumulation of glucosans as a function of endosperm dryweight (Symbols as for Figure 3)

a. Accumulation of starch. b. Accumulation of mixed-link beta-glucan. c. Accumulation of hemicellulose.

development was 9 days slower in the field than in the growth room.

In order that the results obtained from the three cultivars might be compared directly, data were plotted against endosperm dryweight. Figure 4a shows that, as expected, starch content and dryweight were highly correlated for all three cultivars, but that Lami had a higher starch content than Minerva or Triumph in the final stages of kernel growth.

Figure $4 \mathrm{~b}$ compares the accumulation curves of mixed-link beta-glucan for the three cultivars in the experiment. Two different curve shapes are obtained. Minerva accumulates mixed-link beta-glucan at a rate that is relatively high initially, and that increases smoothly as endo- 
sperm weight increases. Lami and Triumph, on the other hand, commence with a relatively low rate of accumulation, which, in the case of Lami, increases to that of Minerva when the endosperm weight increases to $18 \mathrm{mg}$. When endosperm weight reaches $32 \mathrm{mg}$ Triumph shows a sudden large increase in accumulation rate, a phenomenon also observed in Lami at 37 mg dryweight. This endosperm weight corresponds to the time that endosperm moisture content falls below $43 \%$, and moisture loss becomes uncontrolled.

The effect of this spurt is to bring mixed-link beta-glucan content to $85 \%$ of that of Minerva. The accumulation rate then falls, so that by the time that maximum dryweight is obtained the mixed-link beta-glucan content is only $75 \%$ of that of Minerva at the same kernel weight. As noted above, this phenomenon also occurs in Lami, in a more exaggerated way. The mixedlink beta-glucan: dryweight ratio exceeds that of Minerva, before finally declining due to a negative rate of accumulation, so that when final drymatter content is achieved, the content of mixed-link beta-glucan is only $75 \%$ of that in Minerva at the same weight.

Figure $4 c$ compares hemicellulose accumulation curves for the three cultivars. Features of the curves are the very similar patterns observed initially, and the sudden increase in rate in Triumph and Minerva when endosperm dryweight reaches $35 \mathrm{mg}$. This effect, which is not observed in Lami, is connected with the fall of endosperm moisture content below $43 \%$.

\subsection{Phytotron study}

Free sugar curves were similar to each other for Triumph and Minerva, and for all treatments, and indicated the same rate of development as found in Bomi in the growth room. The picture obtained for endosperm development was much as expected. Figure 5a gives the curves of drymatter accumulation for endosperms from treatments 1 (rain) and 2 (root-watering) for both Minerva and Triumph, and it can be seen from this that provision of water as rain leads to lower endosperm weights at all stages, except in Minerva at day 35 . The effect of the rain is greater on Triumph than on Minerva.

Figures $5 \mathrm{c}$ and $5 \mathrm{e}$ give the curves of drymatter accumulation in treatments 3-6 for Triumph and Minerva respectively. In Triumph it can be seen that any imposition of drought (treatments 4,5 or 6) leads to a check in dryweight increase. It is particularly interesting to observe that dryweight increases relatively rapidly at the end of the period of observation in treatment 6 , where an initial stress period is supplanted by normal watering at 20 days after flowering. The increase commences after about day 26 (Figure 5c) at which time, nevertheless, this phenomenon only represents a process of catching up after an initial depression of dryweight. The same phenomenon may be observed in Minerva (Figure 5e), but in this case the depression of dryweight accumulation that was observed in Triumph when late drought stress was applied, did not occur. Consequently, the final drymatter yield in this cultivar was determined by the

Figure 5. Comparison of dryweight and mixed-link beta-glucan accumulation with time after flowering in the phytotron experiments.

The legend inscribed on a curve denotes the watering regime that led to the curve.

5a. Drymatter accumulation for rain (treatment 1 ) and root watering (treatment 2) $\mathrm{M}=$ Minerva, $\mathrm{T}=$ Triumph.

5b. Mixed-linked beta-glucan accumulation for rain (treatment 1) and root watering (treatment 2). $M=$ Minerva, $\mathrm{T}=$ Triumph.

5c. Drymatter accumulation in treatments 3-6 for Triumph.

5d. Mixed-link beta-glucan accumulation in treatments 3-6 for Triumph.

5e. Drymatter accumulation in treatments 3-6 for Minerva.

5f. Mixed-link beta-glucan accumulation in treatments 3-6 for Minerva. For claritys sake treatment numbers are included in the legends. 
G. D. Coles: Beta-glucan accumulation in barley
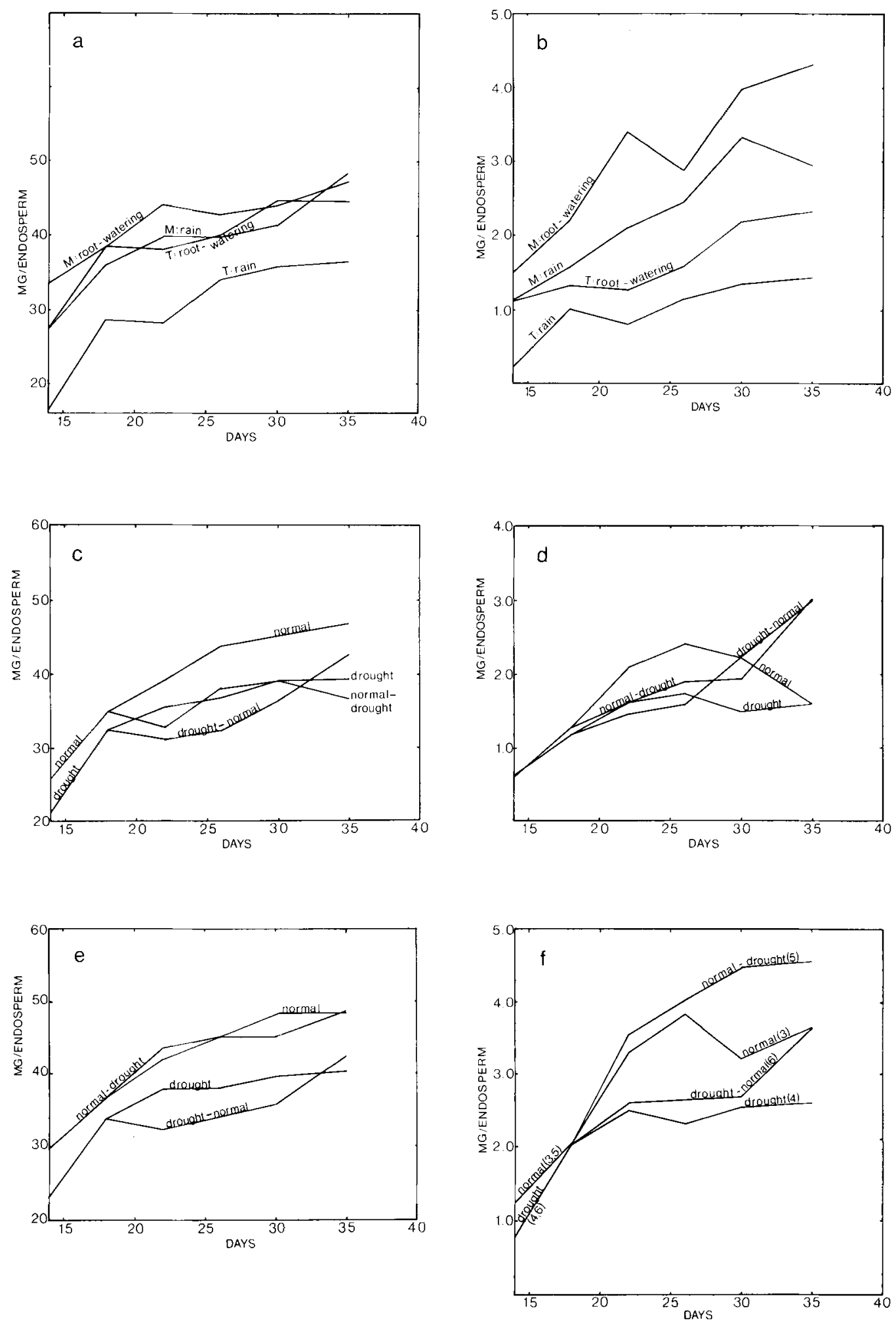
imposition of drought at the beginning of the grain growth period, in contrast to Triumph.

The curves of mixed-link beta-glucan accumulation presented in Figure $5 \mathrm{~b}$ for both Minerva and Triumph clearly show that provision of water in the form of rain gives lower levels of mixed-link beta-glucan content than if similar quantities are supplied directly to the roots. This effect is quite clear in Triumph, even when the difference in the drymatter curves is taken into account. The data obtained thus confirm the results reported by AASTRUP (1).

The data obtained in the drought stress experiment (treatments 3-6) are presented in Figures $5 \mathrm{~d}$ and $5 \mathrm{f}$. Curves of mixed-link betaglucan content for normally-watered samples of Triumph (Figure 5d) and Minerva (Figure 5f) follow the drymatter accumulation pattern until day 26, but from then on total content declines, albeit to a much larger extent in Triumph. Another point of importance in evaluating this experiment is the severe effect continuous drought (treatment 4) had on the growth of endosperms. Kernel moisture content in both Minerva and Triumph declined below $20 \%$ at day 24 and gave rise to severe shrivelling. The effect of this can be observed in the mixed-link beta-glucan curves where, after day 24, no further accumulation took place. Consequently, kernels from this treatment ended up with the lowest mixed-link beta-glucan contents in absolute terms, but with percentage contents that were between those normally-watered and those stressed for only part of the grain growth period. The protein content figures presented in Table II bear out this analysis. When the final harvest was taken at day 35 , total protein was similar in all treatments except in Triumph from the rain treatment, where the final content was reduced by $30 \%$. However, percentage protein content shows a distinct trend towards higher values as drought stress increases. Treatment 4 is an exception to this generalisation, due once again to the disruption of accumulation by forced maturation.

Returning to the figures, it remains to discuss the results obtained when partial drought stress is applied. It may be recalled that in Triumph both late drought and early drought gave rise to broadly similar figures for dryweight increase, compared to normal watering. This uniformity
Table II

Percentage protein content in phytotron produced endosperms from treatments 1-6 (section 2.4.1) at day 35 .

\begin{tabular}{ccc}
\hline Treatment & Minerva & Triumph \\
\hline 1 & 14,6 & 12,2 \\
2 & 14,1 & 14,2 \\
3 & 16,4 & 14,2 \\
4 & 17,4 & 16,9 \\
5 & 17,6 & 16,0 \\
6 & 20,4 & 18,3 \\
\hline
\end{tabular}

of response extends to the results obtained from analysis of beta-glucan content, so that no matter when stress is applied, a similar final result is obtained. The picture obtained for Minerva in this context is apparently quite different, in that late drought stress leads to a much higher absolute content of mixed-link beta-glucan than early stress, but if Figure 5e is recalled it will be remembered that early stress also badly affects kernel dryweight accumulation. Consequently comparison of relative accumulation patterns shows that early and late stress have similar effects, and that both treatments cause increased mixed-link beta-glucan percentages, compared to normal watering.

\section{DISCUSSION}

As indicated in the introduction, this study was undertaken to clarify some points concerning the accumulation of glucosan in barley. It is of interest to review briefly some of the statements made previously by various authors before proceeding.

It is generally accepted that the accumulation of starch, in absolute terms, reflects the curve of dryweight increase. The time of initiation of accumulation is disputed, however. KREIS (26) shows it commencing seven days after flowering and continuing in a more-or-less linear fashion until 35 days after flowering, when his study stopped. Cerning and Guilbot (8) agree with this picture, whereas MACGregor et al. (28), under Canadian conditions, show a slightly later commencement and a very rapid sigmoid increase, tailing off 30 days after flowering. JEN- 
KINS et al. (21) present rather a different picture. They claim that $40 \%$ of grain drymatter at flowering is starch, found in the pericarp, and that the major activity is not de novo synthesis, but transfer of pre-existing material. Their data are confounded by the presence in their samples of non-reducing sugars, pentosan and betaglucan, which they include in the starch fraction. Finally, in an ultrastructural study, Wrulams and Duffus (40) indicate that amyloplast growth (but not necessarily chemically measurable starch deposition) commences about two days after flowering.

A second point on which clarification was required is the relationship between the various physically-fractionated classes of so-called mbarley beta-glucan«, »barley gum《 etc. ANDERSON et al. (4) have detailed the results obtained by various workers for content of barley beta-1,3:1,4-glucan in mature barley, and have outlined an enzymatic method which, instead of relying on the solubility of a rather heterogeneous group of polymers $(12,13)$ in non-standard solvent systems, relies on the solubility of a welldefined group of oligomers in a standard solvent. With slight modifications, this method was adopted in the present investigation.

Significant features of the results of the individual experiments have been pointed out in the relevant sections. It therefore remains to investigate the relationship between the sets of results from different experiments. By comparing timescales for free sugar content it can be seen that starch accumulation in both the field and growth room experiments commences at 12-13 days after flowering. Final starch contents were similar, in Lami and Bomi, to those reported by TORP (38), but lower in Minerva and Triumph. ToRp's method depends on the solubility of polysaccharides in dimethyl sulphoxide, a characteristic not restricted to starch, and the increase in hemicellulose in Minerva and Triumph accounts for the difference.

The interconnection between the two classes of beta-glucosan measured is obvious when Figures $4 \mathrm{~b}$ and $4 \mathrm{c}$ are compared. In all three cultivars, sudden changes in the rate of accumulation of one or other of the classes can be seen. In Triumph this change can be observed for both mixed-link beta-glucan accumulation and for hemicellulose accumulation. Nevertheless, it seems that Triumph has its low final mixed-link beta-glucan content as a result of favouring the synthesis of hemicellulose at this stage. Alternatively, synthesized mixed-link beta-glucan may be further modified to give polymers inaccessible to lichenase (by addition of sidechains, perhaps). The fact that Lami lost mixed-link beta-glucan near maturity while hemicellulose increased is evidence for the second alternative.

It is important to note that though the field experiment was conducted in a season and an environment considered ideal for the production of low-beta-glucan barley, Triumph maintained a substantial advantage over Lami and Minerva in this respect. The phytotron experiment was carried out to see if this advantage persisted under sub-optimal conditions. The experimental protocol outlined in section 2.4.1 encompassed the entire range of moisture supply in which it is possible to grow barley successfully.

The results presented confirm that Triumph has a lower content of mixed-link beta-glucan than Minerva under any of the conditions tested, and that over the range reported mixed-link betaglucan content behaves as predicted. AAsTruP's results (1) are thus confirmed, and it has been possible to isolate drought stress and relative humidity as variables influencing the data reported by SMART (33) and show that they are decisive factors if not the only ones affecting the final content of mixed-link beta-glucan in the barley endosperm.

Reference has already been made to the possibility of using free sugar curves to relate the time scale of experiments conducted in different environments. By comparing results obtained in sections 3.1 and 3.2 with such a time scale transformation in mind, it is possible to see that initiation of synthesis of starch, of mixed-link beta-glucan and of hemicellulose is related to specific levels of free sugar content. As noted by JenNer and RathJen $(23,24)$, however, the regulation of starch-synthesizing ability over time, as opposed to the regulation of the instantaneous rate of starch synthesis is independent of sucrose concentration. This also applies to the other glucosans under consideration.

Cessation of starch synthesis is far more likely to be due to an internal signal (23) connected to the decline in kernel moisture content. Many authors $(2,3,8,19,20,23,24,25,28$, however 
31) have demonstrated, either explicitly or implicitly, that the stage of kernel growth where moisture content is $40-45 \%$ is when starch accumulation declines almost to zero. This stage has been referred to as "physiological maturity" $(7,17,26)$ often while pointing out that changes continue to occur thereafter.

By comparing moisture content of Lami with curves of drymatter accumulation, it may be seen that, at the stage when "physiological maturity « was reached, starch accumulation was nearly complete, whereas it was at this stage that the accumulation rate of other glucosans suddenly increased (Figures $4 \mathrm{~b}$ and $4 \mathrm{c}$ ). These data, the continued increase of dryweight after the moisture content declined below $40 \%$, and results obtained by other workers for protein content $(3,7,19,31$, however 28) and other substances $(2,3,8,17,19,21,23,24,31)$ suggest that assimilate is available at a much later stage than was previously assumed. Furthermore, unpublished data of STOY and Derera (V. STоY, pers. commun.) from wheat show that assimilate deposited in the stem is remobilised at a very late stage and laid down in the grain, implying the existence of a functional link between the grain and the plant up until harvest ripeness.

The data obtained in this study suggest that there is unequal competition for assimilate among the various glucosan-synthesizing mechanisms, the starch mechanism being the most successful in attracting assimilate, and that it is only when the starch-synthesizing machinery declines in activity at $40-45 \%$ moisture that sufficient assimilate becomes available for the other mechanisms to work at capacity. Further work will obviously be required to test this hypothesis.

\section{ACKNOWLEDGEMENTS}

I owe a debt of gratitude to the D.S.I.R., and to Carlsberg Research Laboratory through Professor D. von Wettstein and Dr. LaRs MUNCK for the financial support that permitted the period of study during which the above work was performed. For suggesting the topic, and advice in the initial stages, I would like to thank Professor B. A. STONE of LaTrobe University, Melbourne. Useful discussions were held with
Dr. Munck, Dr. G. C. Grabons and Dr. B. S. ENEVOLDSEN of this Laboratory. The drawing skills of NiNa RASMUSSEN, and the forbearance of my colleagues, and especially my wife, were indispensable.

\section{REFERENCES}

1. Aastrup, $S$.: The effect of rain on $\beta$-glucan content in barley grains. Carlsberg Res. Commun. 44, 381-393 (1979)

2. Abou-Guendia, M. \& B. D. D'Appolonia: Changes in Carbohydrate Components during Wheat Maturation. 1. Changes in Free Sugars. Cereal Chemistry 49, 664-679 (1972)

3. Abou-Guendia, M. \& B. D. D'Appolonia: Changes in Carbohydrates during Wheat Maturation. II, Changes in Sugars, Pentosans and Starch. Cereal Chemistry 50, 723-734 (1973)

4. Anderson, M. A., J. A. Cook \& B. A. Stone: Enzymatic Determination of 1,3:1,4-beta-glucan in Barley Grain and other Cereals. J. Inst. Brew. 84, 233-239 (1978)

5. Bendelow, V. M.: Determination of Non-starch Polysaccharides in Barley Breeding Programmes. J. Inst. Brew. 81, 127-130 (1975)

6. Bewley, J. D. \& M. Bl.ACK: Chap. 3 in »Physiology and Biochemistry of Seeds in Relation to Germination «, Vol. I. Springer-Verlag, New York 1978

7. BRandt, A.: Endosperm Protein Formation during Kernel Development of Wildtype and a High-lysine Barley Mutant. Cereal Chemistry $53,890-901$ (1976)

8. Cerning, J. \& A. Guilbot: Changes in the Carbohydrate Composition during Development and Maturation of the Wheat and Barley Kernel. Cereal Chemistry 50, 220-232 (1973)

9. Delmer, D. P.: The Biosynthesis of Cellulose and other Plant Cell Wall Polysaccharides. pp 45-77 in "The Structure, Biosyntheses and Degradation of Wood火. Recent Advances in Phytochemistry, Vol. II Plenum, London, 1977.

10. Dubois, M., K. A. Gilles, J. K. Hamilton, P. A. Rebers \& F. SMith: Colorimetric Method for Determination of Sugars and Related Substances. Anal. Chem. 28, 350-356 (1956)

11. ERdahl, K. \& P. GJertsen: Beta-glucans in Malting and Brewing. III The Action of Endobeta-glucanases. Proc. 13th European Brewery Congress (1971) pp 49-57, Elsevier Amsterdam

12. Fincher, G. B.: Morphology and Chemical Composition of Barley Endosperm Cell Walls. J. Inst. Brew. 81, 116-122 (1975)

13. Forrest, I. S. \& T. Wainwright: The Mode of 
Binding of Beta-glucans and Pentosans in Barley Endosperm Cell Walls. J. Inst. Brew. 83, 279286 (1977)

14. Forrest, I. S. \& T. Wainwright: Differential between Desirable and Troublesome Betaglucans. Proc. 16th European Brewery Congress (1977) pp 401-413. Elsevier, Amsterdam

15. Gjertsen, P., F. Myken, P. Krogh \& B. Hald: Malting and Brewing Experiments with Ochratoxin and Citrinin. Proc. 14th European Brewery Congress (1973) pp 373-380, Elsevier. Amsterdam

16. GoHL, B.: Effects of Hydrocolloids on Productive Value and Feeding Characteristics of Barley. Dissertation to the Department of Animal Husbandry of the Agricultural University of Sweden. ISBN 91-7088-680-6

17. Gordon, I. L., L. N. Bal.aam \& N. F. Derera: Selection against Sprouting Damage in Wheat. II Harvest Ripeness, Grain Maturity, and Germinability. Aust. J. Agric. Res. 30, 1-17 (1979)

18. Harris, G. \& I. C. MaCW illiam: Carbohydrates in Malting and Brewing. II. Changes in the Carbohydrates of Barley during Ripening, Harvest and Storage. J. Inst. Brew. 60, 387-392 (1954)

19. Harris, G. \& I. C. MaCW illiam: Carbohydrates in Malting and Brewing. VI. Changes in the Carbohydrates Composition of Barley on Ripening and Corresponding Variations in Nitrogenous Constituents. J. Inst. Brew. 63, 210-220 (1957)

20. Jenkins, L. D., P. Meredith \& D. P. Loney: The Developing Starch Granule. Pt. I. The Starch Content of Cereal Grains during their Development. Die Starke 27, 105-109 (1975)

21. Jenkins, L. D., D. P. Loney, P. Meredith \& B. A. Finfran: Periodicity of Growth and Starch Deposition in the Developing Wheat Grain. Cereal Chem. 51, 718-733 (1974)

22. JenNer, C. F: Relationship Between Levels of Soluble Carbohydrate and Starch Synthesis in Detached Ears of Wheat. Aust. J. Biol. Sci. 23 . 991-1003 (1970)

23. Jenner, C. F. \& A. J. Rathjen: Factors Regulating the Accumulation of Starch in Ripening Wheat Grain. Aust. J. Plant Physiol. 2, 311-322 (1975)

24. Jenner, C. F. \& A. J. Rathuen: Supply of Sucrose and its Metabolism in Developing Grains of Wheat. Aust. J. Plant Physiol. 4, 691701 (1977)

25. Jennings, A. C. \& R. K. Morton: Changes in Carbohydrate, Protein and Non-protein Nitrogenous Compounds of Developing Wheat Grains. Aust. J. Biol. Sci. 16, 318-331 (1963)
26. Kreis, M.: Starch and Free sugars Kernel Development of Bomi Barley and its High-lysine Mutant 1508, pp 115-120 in wSeed Improvement by Nuclear Techniques«. IAEA-RC-57/12 (1978)

27. LaBerge, D. E., A. W. MacGregor \& W. O. S. Meredith: Changes in the Free Sugar Content of Barley Kernels during Maturation. J. Inst. Brew, 79

28. MacGregor, A. W., D. E. LaBerge \& W. O. S. Meredith: Changes in Barley Kernels during Growth and Maturation. Cereal Chem. 48, 255269 (1971)

29. MacNeil, M., P. Albersheim, L. Talz \& R. C. JoNes: The Structure of Plant Cell Walls. VII. Barley Aleurone Cells. Plant Physiol 55, 64-68 (1975)

30. Meredith, P. \& J. D. Jenkins: The Weight of the Mature Wheat Grain. Planta 94, 233 (1970)

31. Merritr, N. R. \& J. T. Walker: Development of Starch and other Components in Normal and High amylose Barley. J. Inst. Brew. 75, 156164 (1969)

32. Morgan, A. G.: The Relationship Between Barley Extract Viscosity Curves and Malting Ability. I. Inst. Brew. 83, 231-234 (1977)

33. Smart, J. G.: The Beta-glucan Content of New Zealand Barleys. Proc. 14th Ann. Meeting Aust. N. Z. Section lnst. Brew. pp 161-168

34. Smith, M. M. \& B. A. Stone: Beta-glucan Synthesis by Cell-free Lolium multiflorum Endosperm. Biochim. Biophys. Acta 313, 72-94

35. Southgate, D. A. T., G. J. Hudson \& H. ENGLYST: The Analysis of Dietary Fibre - The Choices for the Analyst. J. Sci. Fd. Agric. 29, 979-988 (1978)

36. Sparrow, D. H. B. \& W. O. S. Meredith: Malt Cytolytic activity of Barleys of Diverse Origins and its Relation to Maltability. J. Inst. Brew 75 , 237-242 (1969)

37. Тномке, S.: On the Influence if Different Stages of Ripeness on the Productive Value of Barley Fed to Chickens, Laying Hens, Rats and Mice. Acta Agriculturae Scandinavica 22, 107-120 (1972)

38. TORP, J.: Relations between the Production of Starch and the Percentage, Quality and Yield of Protein in Barley. Zeitschrift für Pflanzen- und Agerbau (in press)

39. Wettstein, D. von: The Phytotron in Stockholm. Studia Forestalia Suecica. No. 44 (1967)

40. Williams, J. M. \& C. M. Duffus: The Development of Endosperm Amyloplasts during Grain Maturation in Barley. J. Inst. Brew. 84, 47-50 (1978) 